Bài báo khoa học

\title{
Đánh giá khả năng ứng dụng công nghệ Radar quan trắc lưu lượng nước tự động tại một số các trạm thủy văn hạng I khu vực Tây Bắc và Việt Bắc
}

\author{
Trần Ngọc Anh ${ }^{*}$, La Đức Dũng ${ }^{2}$, Lý Tuấn Minh ${ }^{1}$, Trần Vinh Quang ${ }^{1}$, Hoàng Thái \\ Bình $^{3}$, Phạm Duy Huy Bình ${ }^{1}$, Nguyễn Văn Nguyên², Nguyễn Phụ Luân²
}

${ }^{1}$ Trung tâm Động lực học Thủy khí Môi trường, Trường Đại học Khoa học Tự nhiên, Đại học Quốc gia Hà Nội; tranngocanh@hus.edu.vn; lytuanminh122@gmail.com; tranvinhquang@hus.edu.vn; phambinh@hus.edu.vn

${ }^{2}$ Tổng cục Khí tượng Thủy văn, Bộ Tài nguyên và Môi trường; dunglakttv@gmail.com; nguyentaybac@gmail.com; luansdu@gmail.com

${ }^{3}$ Viện Địa lý, Viện hàn lâm Khoa học và Công nghệ Việt Nam; binhht060774@gmail.com

*Tác giả liên hệ: tranngocanh@hus.edu.vn; Tel.: +84-915051515

Ban Biên tập nhận bài: 1/7/2021; Ngày phản biện xong: 7/8/2021; Ngày đăng bài: 25/9/2021

Tóm tắt: Các công nghệ quan trắc tự động hóa như đo lưu lượng nước bằng Radar đang được lựa chọn triển khai lần đầu ở Việt Nam tại một số các trạm thủy văn do có nhiều ưu điểm về tính liên tục và mật độ dữ liệu, an toàn cho quan trắc viên và hạn chế các sai số chủ quan. Tuy nhiên, đã có những quan ngại về mức độ khả thi và tính chính xác của dữ liệu theo công nghệ mới này và vì vậy cần có các đánh giá cụ thể và chi tiết hơn. Bài báo này tập trung đánh giá về khả năng ứng dụng công nghệ Radar quan trắc lưu lượng tự động (phi tiếp xúc) sử dụng số liệu tại một số trạm thủy văn có quan trắc lưu lượng khu vực Tây Bắc và Việt Bắc, thông qua đánh giá chất lượng mối quan hệ $Q \sim\left(V_{m a ̣ ̆ t}, H\right)$ so với quan hệ $Q \sim H$ theo truyền thống. Kết quả cho thấy, bên cạnh các ưu điểm nêu trên, công nghệ Radar có tiềm năng cung cấp dữ liệu tương đối chính xác tại các trạm có chế độ dòng chảy ổn định và tăng cường mức độ tin cậy ở các trạm có chế độ tương đối phức tạp như hiện tượng nước vật nhưng chưa được đánh giá với các trạm thủy văn có chế độ phức tạp hơn như chảy ngược hay có ảnh hưởng của dòng triều.

Từ khóa: Quan trắc lưu lượng tự động; Công nghệ quan trắc bằng Radar; Tây Bắc; Việt Bắc.

\section{Mở đầu}

Mạng lưới trạm quan trắc khí tượng thủy văn nước ta đã được xây dựng từ những năm đầu của thế kỷ trước và được quan tâm đầu tư mạnh mẽ trong những năm gần đây, tuy nhiên, vẫn còn có nhiều trạm quan trắc thủy văn đang sử dụng các phương pháp đo thủ công hoặc bán thủ công và vì thế đã ảnh hưởng đến chất lượng số liệu, sự an toàn của quan trắc viền cũng như chưa đáp ứng được tính tức thời và tần suất của số liệu quan trắc phục vụ công tác dự báo và cảnh báo thiên tai. Trong số các yếu tố quan trắc thủy văn, lưu lượng nước sông là một yếu tố rất quan trọng, được sử dụng trong nhiều ngành và lĩnh vực khác nhau, nhất là quản lý tài nguyên nước, thủy điện, thủy lợi... nhưng công tác quan trắc còn gặp nhiều khó khăn [1-2]. Các phương pháp hiện đại, chính xác để đo trực tiếp và tức thời lưu lượng nước (sau đây gọi tắt là lưu lượng) thường chỉ thuận lợi với các kênh nhân tạo, các đường ống dẫn nước hoặc trong các đoạn sông đặc thù và thường khó khả thi trong sông thiên nhiên với 
nhiều biến đổi bất quy tắc và điều kiện áp dụng phức tạp [3-4]. Do vậy, các phương pháp phổ biến để quan trắc hiện nay (cả tự động, bán tự động hay thủ công) đều đo lưu tốc và diện tích mặt cắt ngang để từ đó tính toán ra giá trị lưu lượng tại trạm quan trắc [3].

Khi sử dụng phương pháp thủ công quan trắc lưu lượng trên sông, thường mất nhiều thời gian nhất là trong điều kiện lũ lớn, do vậy số liệu thường chứa đựng nhiều sai số, nguy hiểm cho quan trắc viên làm việc trực tiếp trên sông và khó lòng quan trắc kịp thời để xác định được diễn biến của các sự kiện xảy ra nhanh như lũ trên một số các sông suối khu vực phía bắc và miền trung nước ta. Các phương pháp hiện đại đã được đề xuất để ứng dụng các công nghệ mới hướng đến quan trắc tự động, từ xa (không tiếp xúc trực tiếp với dòng nước) và có nhiều ứng dụng thành công trên thế giới [5-9] như tại Mỹ, Hà Lan, Bỉ, Nhật... Gần đây, các thiết bị đo lưu tốc sử dụng công nghệ Radar đang được quan tâm nghiên cứu và đề xuất đầu tư ở Việt Nam do ưu điểm quan trắc không cần tiếp xúc với dòng chảy, phương pháp lắp đặt đơn giản, có thể lắp trên các công trình hiện có như cầu giao thông, cống ngăn dòng, có thể quan trắc tự động và liên tục. Một số thiết bị đã được đề xuất sử dụng trong các dự án đầu tư cụ thể như: "Quan trắc giám sát, nguồn nước xuyên biên giới Việt Nam - Trung Quốc" do Cục Quản lý tài nguyên nước làm chủ đầu tư, trong đó đầu tư 8 trạm sử dụng thiết bị quan trắc lưu lượng tự động công nghệ radar (RQ30), "Quản lý tổng hơp tài nguyên nước Mê Công" do Bộ Tài nguyên và Môi trường làm chủ đầu tư, trong đó đầu tư 10 trạm quan trắc tài nguyên nước, 14 trạm thủy văn đo lưu lượng tự động sử dụng thiết bị radar (RQ30); "Đầu tu xây dưng mạng lưới quan trắc giám sát tài nguyên nước và tăng cuờng công tác điều phối việc vận hành liên hồ chưa trên luu vưc sông Vu Gia - Thu Bồn và luu vưc sông Cả" thuộc Hợp phần 2 của Dự án "Sứa chũa và nâng cao an toàn đập" (WB8) do Tổng cục Khí tượng Thủy văn làm chủ đầu tư, đang chuẩn bị đầu tư lắp đặt 17 thiết bị đo lưu lượng tự động không tiếp xúc cho các trạm thủy văn, tài nguyên nước... và đang có một số quan ngại về tính khả thi và mức độ chính xác của việc triển khai các hệ thống thiết bị công nghệ mới này.

Tuy việc nghiên cứu đánh giá tính chính xác và khả năng áp dụng của công nghệ radar đã được chú ý từ lâu trên thế giới [9] qua việc phân tích đánh giá trong phòng thí nghiệm [8] cũng như tại thực tiễn các sông, suối $[4,7,9,11]$ đã cho thấy tiềm năng trong thực tế của công nghệ phụ thuộc vào các điều kiện cụ thể của sông ngòi. Nhưng tại Việt Nam vẫn chưa có nghiên cứu cụ thể để xác định, đặc biệt với hệ thống trạm hiện nay trên mạng lưới trạm quan trắc thuộc Tổng cục Khí tượng Thủy văn. Nguyên lý chung của hệ thống quan trắc lưu lượng bằng công nghệ radar là đưa "thêm" lưu tốc mặt tại (một số) thủy trực đại biểu được quan trắc trực tiếp bằng sensor lưu tốc và cùng với giá trị mực nước tức thời quan trắc bằng sensor đo khoảng cách để xác định được quan hệ với lưu lượng chảy qua mặt cắt ngang [12], từ đó tăng cường mức độ chính xác so với không có đo lưu tốc và vẫn đáp ứng về tính "không tiếp xúc" và tự động, liên tục của công nghệ. Nghiên cứu này thu thập dữ liệu hiện có tại một số trạm thủy văn có quan trắc lưu lượng tại khu vực Tây Bắc và Việt Bắc, phân tích, đánh giá chuỗi số liệu để xác định thủy trực có quan hệ tốt với lưu tốc trung bình mặt cắt và tính toán lưu lượng từ giá trị lưu tốc mặt và mực nước tại mỗi thời điểm, qua đó đánh giá tính khả thi của việc tăng cường độ chính xác và thay thế phương pháp quan trắc hiện nay bằng việc xây dựng mối quan hệ giữa lưu lượng với mực nước và lưu tốc mặt. Điều đó sẽ gián tiếp khẳng định tiềm năng lắp đặt thiết bị đo lưu tốc bằng công nghệ radar để quan trắc lưu lượng tại các trạm được đánh giá. Phương pháp này cũng sẽ được sử dụng cho các trạm còn lại có dữ liệu để xác định sơ bộ khả năng lắp đặt trước khi tiến hành các khảo sát kỹ lưỡng hơn về các điều kiện cụ thể như công trình lắp đặt để khống chế điểm đo mực nước, xác định thủy trực đo lưu tốc, cách thức truyền số liệu và các yếu tố có liên quan khác.

\section{Giới thiệu về khu vực và phương pháp nghiên cứu}

\subsection{Khu vục nghiên cứu}

Nghiên cứu được thực hiện tại các tỉnh thuộc khu vực Tây Bắc, Việt Bắc, nằm trong các lưu vực sông Hồng-Thái Bình và lưu vực sông Mã bao gồm: Lai Châu, Điện Biên, Sơn La, 
Hòa Bình, Hà Giang, Tuyên Quang, Lào Cai, Yên Bái, Thái Nguyên, Bắc Kạn, Phú Thọ và Vĩnh Phúc (Hình 1).

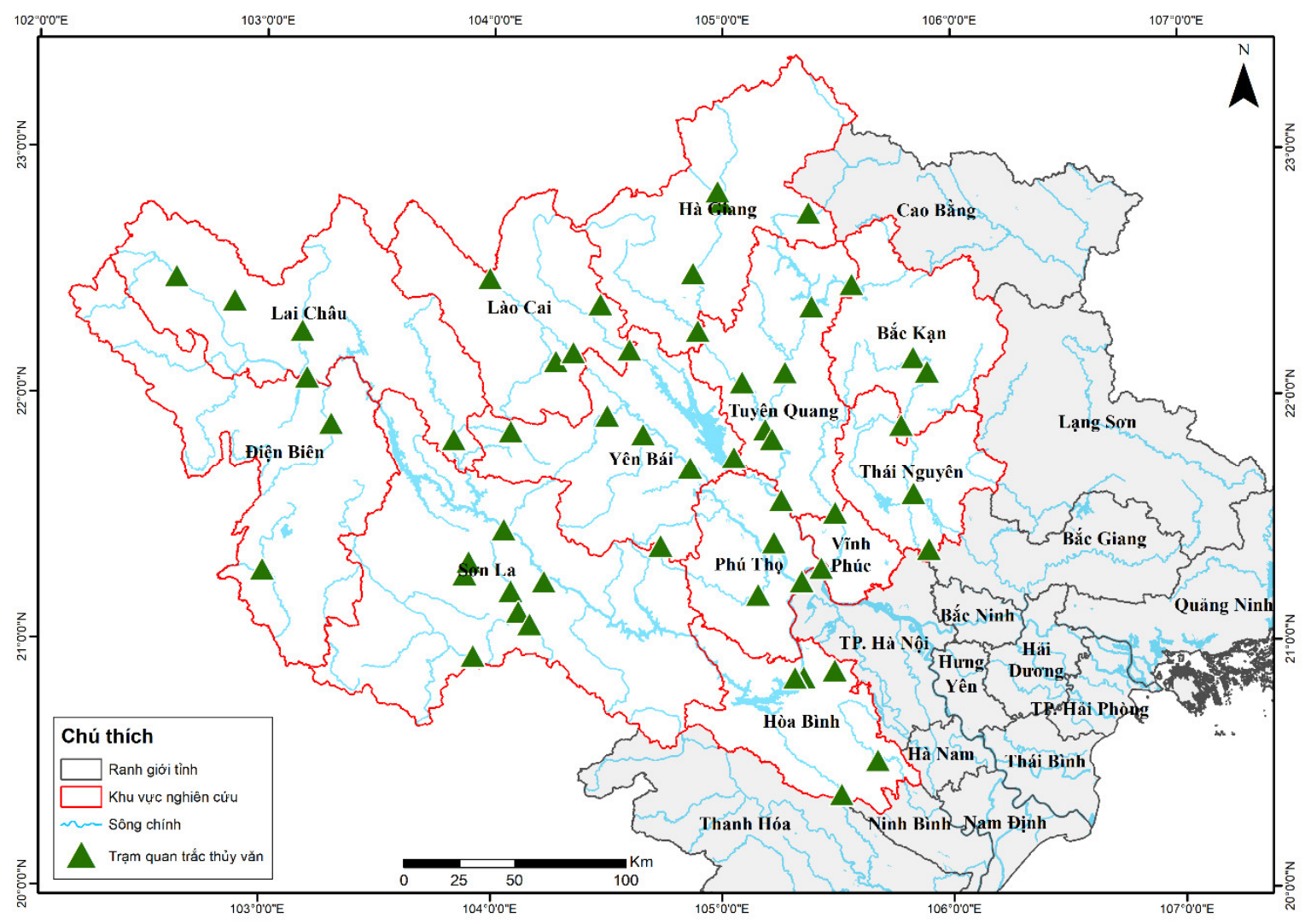

Hình 1. Bản đồ mạng lưới trạm quan trắc thủy văn khu vực Tây Bắc và Việt Bắc.

\subsection{Khảo sát thục địa}

Trong quá trình thực hiện nghiên cứu, nhóm tác giả đã đến thực địa tại một số trạm thủy văn trong khu vực để tiến hành khảo sát sơ bộ hiện trạng quan trắc và tính khả thi ban đầu của việc áp dụng phương pháp quan trắc tự động bằng công nghệ Radar (Hình 2-3).
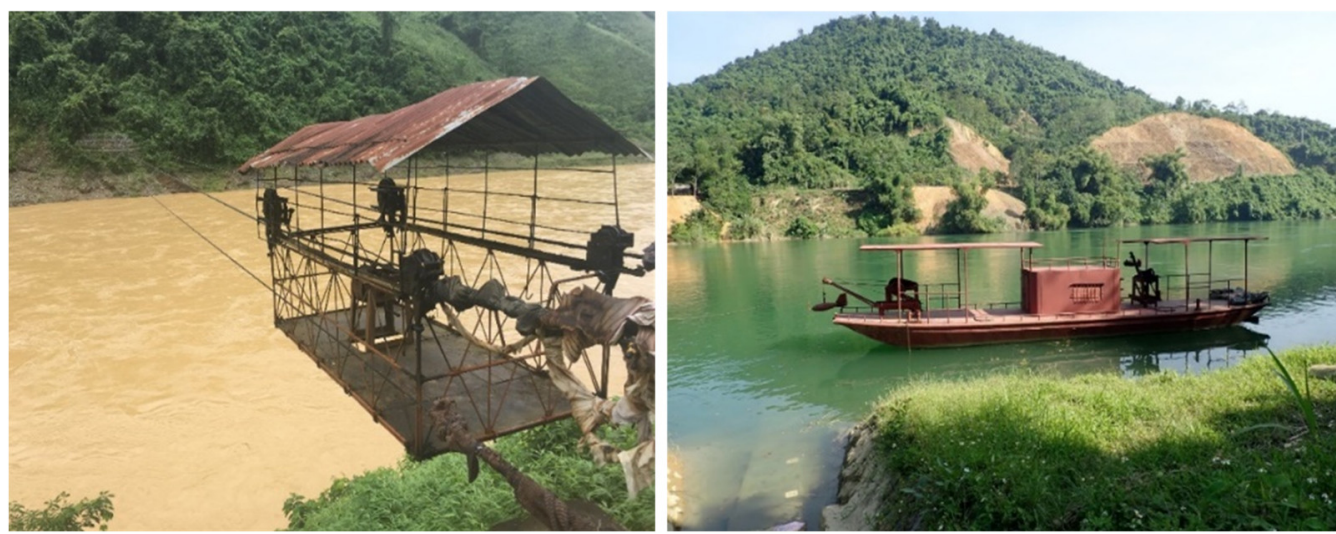

Hình 2. Một số hình ảnh khảo sát thực địa tại các trạm được sử dụng để nghiên cứu đánh giá.

\subsection{Phuơng pháp, nguyên lý và số liệu}

\subsubsection{Tổng quan về công nghệ Radar quan trắc mực nước tự động}

Thiết bị đo lưu lượng và mực nước không tiếp xúc sử sụng sóng Radar là loại thiết bị tiên tiến, có thể gắn cố định trên thành cầu hoặc các công trình đo với nguyên lý phản xạ sóng từ mặt nước. Ưu điểm của loại thiết bị này là có thể gắn cố định tại vị trí (các) thủy trực 
đại biểu của dòng chảy, kết hợp với mực nước và mặt cắt ngang sông đã được cập nhật tại vị trí quan trắc để xác định lưu lượng, có thể đo liên tục và truyền phát số liệu tự động, có thể ứng dụng cho các sông có công trình cứng (cầu, đảo, trụ, cánh tay đòn) khống chể được dao động mực nước và thủy trực đại biểu (Hình 3) hoặc có thể gắn trên công trình đo bằng cáp treo ngang sông hoặc cáp tự hành [3]. Thiết bị quan trắc sử dụng loại công nghệ này đã được phát triển và áp dụng ở nhiểu nước trên thế giới như tại Italia, Mỹ, Úc,... và đã chứng tỏ được sự linh hoạt và ưu điểm của công nghệ này .

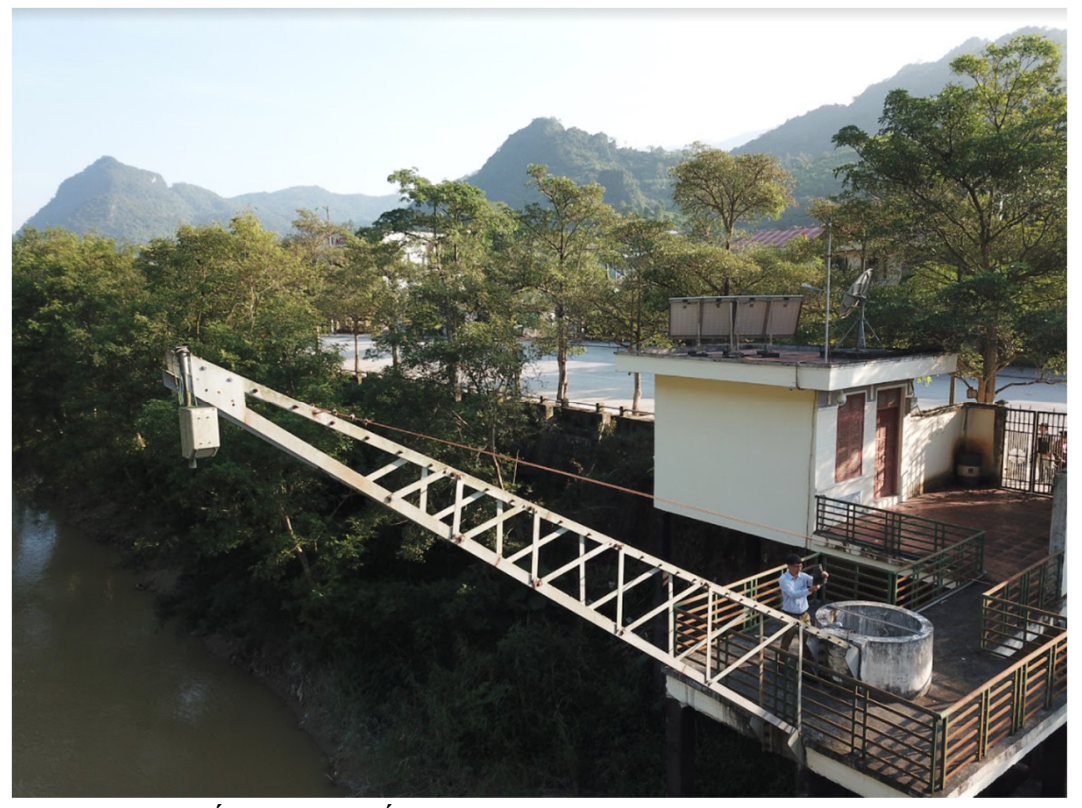

Hình 3. Hình ảnh thiết bị RQ30 lắp đặt tại trạm Tài nguyên nước Thanh Thủy, Hà Giang.

\subsubsection{Nguyên lý hoạt động, tính toán lưu lượng}

Với công nghệ Radar quan trắc lưu lượng tự động, có nhiều hệ thống thiết bị khác nhau đã được chế tạo và thử nghiệm, có hệ thống bao gồm cả 3 thành phần: hệ thống Radar (xuyên đất) đo mặt cắt ngang sông được bố trí ở nhiều điểm khác nhau trên mặt cắt ngang [6-7], Radar đo mực nước và Radar đo lưu tốc bề mặt [12]; có hệ thống chỉ gồm 2 hệ thống Radar đo mực nước và lưu tốc bề mặt. Trong đó loại thiết bị đầu tiên có độ chính xác cao hơn và có thể áp dụng cho cả các khu vực lòng sông thiếu ổn định trong khi loại thiết bị sau thì ứng dụng đơn giản hơn, không yêu cầu khắt khe về công trình lắp đặt nhưng chỉ phù hợp ở khu vực lòng sông ổn định. Trong điều kiện hiện nay ở Việt Nam, có sự quan tâm lớn dành cho loại thiết bị đo mực nước và vận đốc đồng thời, do vậy nó sẽ là ưu tiên trong khuôn khổ bài báo này để đánh giá tiềm năng lắp đặt ở một số các trạm đo ở khu vực Tây Bắc và Việt Bắc.

a) Mực nước

Mực nước được tính bằng cách sử dụng phép đo thời gian truyền và nhận tín hiệu. Radar gửi các xung ngắn theo phương vuông góc với mặt nước. Thời gian truyền và nhận các xung này sẽ được ghi lại, từ đó tính toán được khoảng cách từ thiết bị đến mặt nước và xác định mực nước $[3,6-8]$. Nhìn chung, yêu cầu lắp đặt sensor phải vuông góc với mặt nước và khống chế được mực nước cao nhất và thấp nhất hoặc bố trí nhiều sensor.

b) Lưu tốc

Lưu tốc dòng chảy được quan trắc dựa trên sự thay đổi tần số Doppler. Một tín hiệu radar có tần số $24 \mathrm{GHz}$ được truyền về phía mặt nước. Tín hiệu bị phản xạ một phần, nước chuyển động gây ra sự thay đổi tần số do hiệu ứng Doppler. Lưu tốc bề mặt được tính toán dựa trên tín hiệu phản xạ này qua một phép phân tích quang phổ. Tín hiệu phải được truyền đi một góc so với mặt nước, giá trị của góc này được phần mềm đo lại để tự động hiệu chỉnh lưu tốc tính toán $[3,6-8,12]$ (Hình 4). 


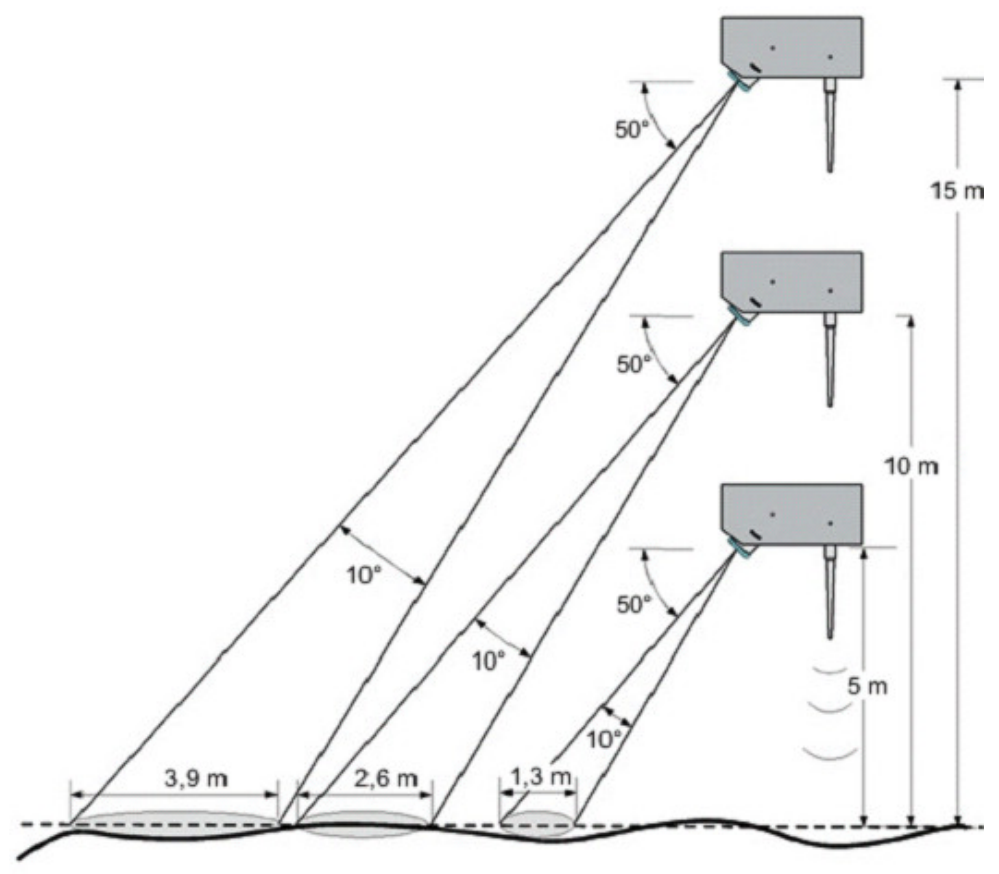

Hình 4. Minh họa phương pháp quan trắc lưu lượng của hệ thống Radar [12].

c) Tính toán lưu lượng

Lưu lượng $Q$ sẽ được tính toán bởi công thức [12]:

$$
\mathrm{Q}=\mathrm{V}_{\mathrm{tb}} * \mathrm{~A}(\mathrm{H})
$$

Trong đó $\mathrm{A}$ là diện tích mặt cắt ngang ứng với mực nước $\mathrm{H}$, phụ thuộc vào hình dạng mặt cắt ngang (thường đã được nhập sẵn trong phần mềm tính toán), $\mathrm{V}_{\mathrm{t}}$ là lưu tốc trung bình mặt cắt. Do hệ thống RQ30 không đo được $\mathrm{V}_{\mathrm{tb}}$ mà chỉ đo được lưu tốc bề mặt $\mathrm{V}_{\mathrm{m}}$, lưu tốc trung bình được tính toán nhờ hệ số chuyển đổi $\mathrm{k}$ qua công thức:

$$
\mathrm{V}_{\mathrm{tb}}=\mathrm{V}_{\mathrm{m}} * \mathrm{k}
$$

Hệ số $\mathrm{k}$ có thể được xác định bởi các phép đo tham chiếu và xác định trước, sau đó dựa trên mực nước và lưu tốc mặt, hệ thống có thể xác định liên tục giá trị Q theo thời gian.

\subsubsection{Phương pháp đánh giá}

a) Số liệu

Các số liệu được sử dụng trong nghiên cứu này được thu thập từ sổ đo chi tiết lưu lượng của các trạm thủy văn trong khu vực nghiên cứu gồm có 8 trạm (Bảng 1). Do công nghệ Radar chỉ đo đạc lưu tốc bề mặt nên để có thể xác định được vị trí thủy trực phù hợp lắp đặt sensor đo lưu tốc, chỉ các thủy trực đo theo phương pháp 3 điểm trở lên (để xác định được giá trị lưu tốc mặt) mới được sử dụng để đánh giá mức độ tương quan giữa lưu tốc bề mặt với lưu tốc trung bình mặt cắt. Tại mỗi trạm, có ít nhất 50 số liệu đo quan trắc lưu lượng, đảm bảo khống chế đầy đủ và bố trí tương đối đều từ mực nước thấp nhất đến cao nhất trong giai đoạn 2017-2020, được xử lý và đưa vào đánh giá nhằm đảm bảo độ tin cậy của các quan hệ thống kê. Một số các trạm khác đang sử dụng $\mathrm{ADCP}$, về nguyên tắc có thể trích xuất thông tin về phân bố lưu tốc trên thủy trực từ mặt xuống đáy, nhưng do hạn chế về phần mềm nên trong nghiên cứu này chưa có điều kiện đánh giá. Mặt khác, để đảm bảo an toàn cho quan trắc viên, một số ca đo lưu lượng trong điều kiện lũ lền nhanh, lũ lớn, mất ổn định do đóng mở cửa xả thủy điện, lũ nguy hiểm,... các trạm đo đã áp dụng phương án đo giảm đường, giảm điểm, trong nhiều trường hợp chỉ đo lưu tốc tại 1 điểm trên thủy trực đại biểu (ứng với $0,6 \mathrm{~h}$ ) do vậy thiếu số liệu quan trắc lưu tốc mặt để đánh giá. Điều này đã hạn chế số lượng dữ liệu có thể đưa vào tính toán ở các trạm. 
Bảng 1. Thống kê số liệu của các trạm được dùng để đánh giá.

\begin{tabular}{ccccc}
\hline STT & Trạm & Sông & Năm số liệu & Chuỗi số liệu \\
\hline 1 & Nậm Giàng & Nậm Na & $2019-2020$ & 55 lần đo \\
2 & Hoà Bình & Đà & $2017-2019$ & 61 lần đo \\
3 & Na Sang & Nậm Mức & $2018-2019$ & 49 lần đo \\
4 & Đầu Đằng & Gâm & $2018-2019$ & 113 lần đo \\
5 & Bảo Yên & Chảy & $2018-2019$ & 53 lần đo \\
6 & Yên Bái & Hồng & $2018-2019$ & 111 lần đo \\
7 & Chiêm Hóa & Gâm & $2018-2019$ & 43 lần đo \\
8 & Lào Cai & Hồng & $2018-2019$ & 98 lần đo \\
\hline
\end{tabular}

b) Phương pháp

Dựa vào chuỗi số liệu của các trạm thủy văn, tùy theo độ dài chuỗi mà sẽ chọn lọc một khoảng dữ liệu (chuỗi dữ liệu 1) để kiểm tra, lựa chọn thủy trực đại biểu và tính toán hệ số k. Sau khi đã có có được những thông số này, khoảng dữ liệu còn lại (chuỗi dữ liệu 2) sẽ được sử dụng để tính toán $\mathrm{V}_{\mathrm{tb}}$ từ $\mathrm{V}_{\mathrm{m}}$ của thủy trực đã lựa chọn trước đó. Đưa giá trị $\mathrm{V}_{\mathrm{tb}}$ vào công thức (1), ta tính được lưu lượng mô phỏng theo phương pháp tính toán của Radar. Sau đó các giá trị này sẽ được so sánh với các giá trị lưu lượng thực đo có trong sổ đo của trạm, để đánh giá được khả năng ứng dụng công nghệ Radar quan trắc lưu lượng tự động (Hình 5).

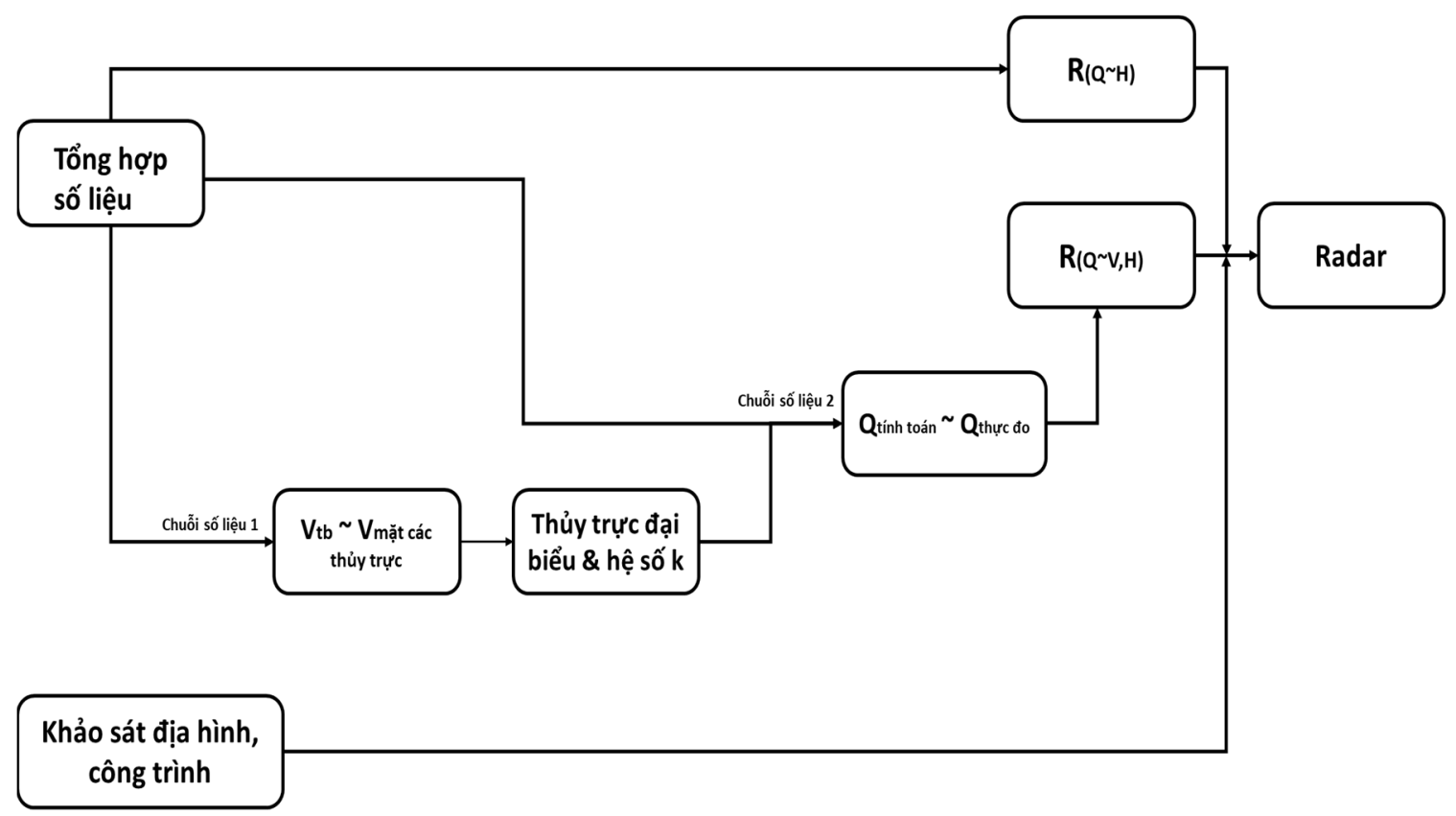

Hình 5. Phương pháp đánh giá tương quan cho việc nghiên cứu áp dụng Radar.

\section{Kết quả và thảo luận}

\subsection{Lụa chọn thủy trục đại biểu tại các trạm}

Chuỗi số liệu 61 lần đo tại trạm Thủy văn Hòa Bình đã được trích xuất gồm có lưu tốc bề mặt $\mathrm{V}_{\mathrm{m}}$ (giả thiết bằng với số đo tại điểm $0,2 \mathrm{~h}$ ) tại 11 thủy trực và giá trị lưu tốc trung bình mặt cắt được tính toán theo quy phạm để hình thành 11 cặp chuỗi thống kê và tiến hành tính toán mức độ tương quan. Kết quả cho thấy $\mathrm{V}_{\mathrm{m}}$ tại thủy trực số 9 , cho hệ số tương quan cao nhất, $\mathrm{k}=0,99$ và sẽ được sử dụng để xác định lưu lượng từ giá trị $\mathrm{V}_{\mathrm{m}}$ quan trắc này (Hình 6). Quy trình tương tự được xác định cho các trạm thủy văn còn lại với các kết quả trình bày trong Bảng 2. 

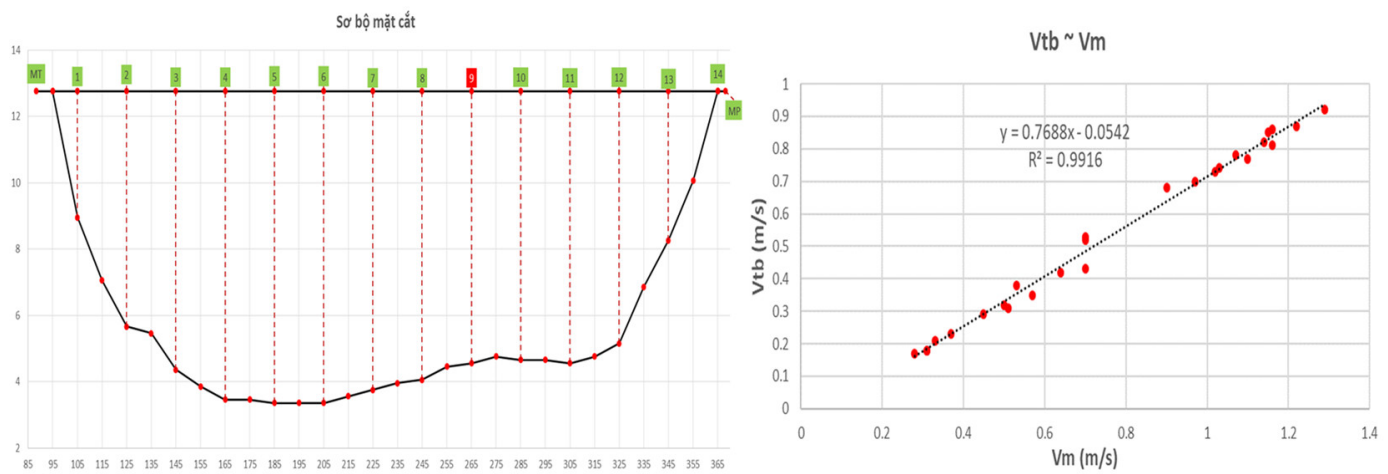

Hình 6. Mặt cắt ngang trạm Hòa Bình và quan hệ lưu tốc mặt tại thủy trực “đại biểu” với lưu tốc trung bình mặt cắt ngang.

Bảng 2. Xác định thủy trực lắp đặt sensor đo lưu tốc và hệ số k tại các trạm thủy văn.

\begin{tabular}{|c|c|c|c|c|c|c|}
\hline TT & Tên trạm & $\begin{array}{l}\text { Tổng số thủy } \\
\text { trực quan trắc }\end{array}$ & $\begin{array}{l}\text { Số lượng thủy } \\
\text { trực có số liệu } V_{m}\end{array}$ & $\begin{array}{c}\text { Số hiệu thủy trực } \\
\text { đại biểu về } V_{m}\end{array}$ & $\begin{array}{l}\text { Hệ số tương } \\
\text { quan } V_{t b} \sim V_{m}\end{array}$ & Hệ số $k$ \\
\hline 1 & Hòa Bình & 14 & 11 & 9 & 0,99 & 0,76 \\
\hline 2 & $\begin{array}{l}\text { Nậm } \\
\text { Giàng }\end{array}$ & 12 & 10 & 4 & 0,94 & 0,9 \\
\hline 3 & Na Sang & 9 & 6 & 6 & 0,98 & 0,77 \\
\hline 4 & Đầu Đẳng & 14 & 8 & 12 & 0,99 & 0,73 \\
\hline 5 & Bảo Yên & 11 & 10 & 7 & 0,98 & 0,74 \\
\hline 6 & Yên Bái & 9 & 7 & 7 & 0,97 & 0,86 \\
\hline 7 & $\begin{array}{l}\text { Chiêm } \\
\text { Hóa }\end{array}$ & 9 & 7 & 5 & 0,98 & 0,72 \\
\hline 8 & Lào Cai & 9 & 7 & 8 & 0,99 & 0,95 \\
\hline
\end{tabular}

\section{2. Đánh giá kết quả mô phỏng $Q$ theo quan hệ $(Q \sim H)$ và $Q \sim\left(H, V_{m}\right)$}

Sau khi đã xác định được thủy trực đo lưu tốc bề mặt, với mỗi lần đo sẽ xác định được $\mathrm{V}_{\mathrm{tb}}$ theo công thức (2) và tính diện tích mặt cắt ướt $\mathrm{A}(\mathrm{H})$ tương ứng để xác định được $\mathrm{Q}_{\text {radar }}$ theo công thức (1). Mỗi lần đo sẽ có giá trị $\mathrm{Q}_{\text {radar, }} \mathrm{V}_{\mathrm{m}}$ và $\mathrm{H}_{\text {thucdo, }}$, để từ đó xác định các quan hệ $\mathrm{Q}_{\text {thucdo }} \sim \mathrm{H}_{\text {thuudo }}$ và hệ số tương quan giữa $\mathrm{Q}_{\text {thucdo }} \sim \mathrm{Q}_{\text {radar }}=\mathrm{f}\left(\mathrm{H}, \mathrm{V}_{\mathrm{m}}\right)$ với các hệ số tương quan tương ứng. Các kết quả tính toán biểu diễn trên các Hình 7-14 và tổng hợp trong Bảng 3 .
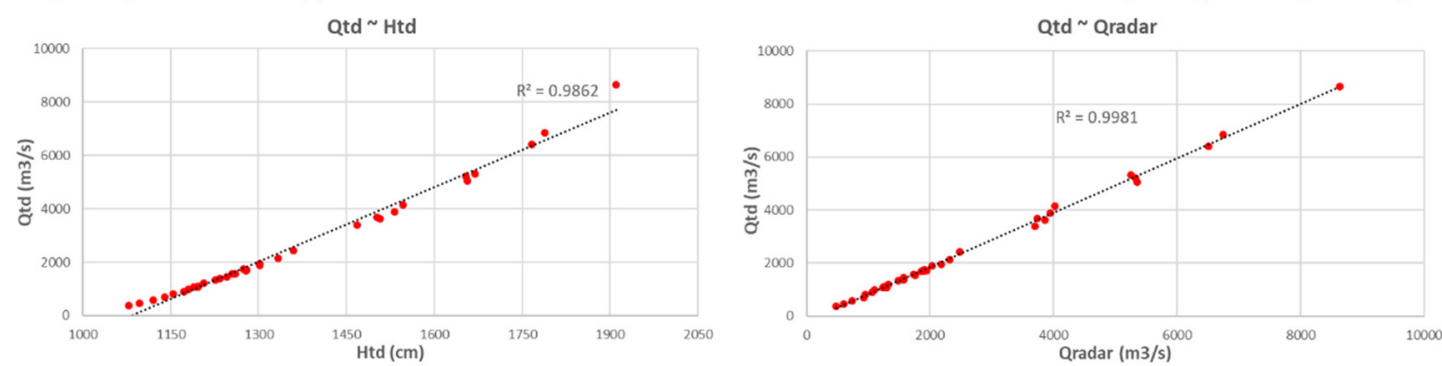

Hình 7. Quan hệ $\mathrm{Q}_{\text {thucdo }} \sim \mathrm{H}_{\text {thucdo }}$ (trái) và quan hệ giữa $\mathrm{Q}_{\text {thucdo }} \sim \mathrm{Q}_{\text {radar }}$ (phải) tại trạm Hòa Bình.
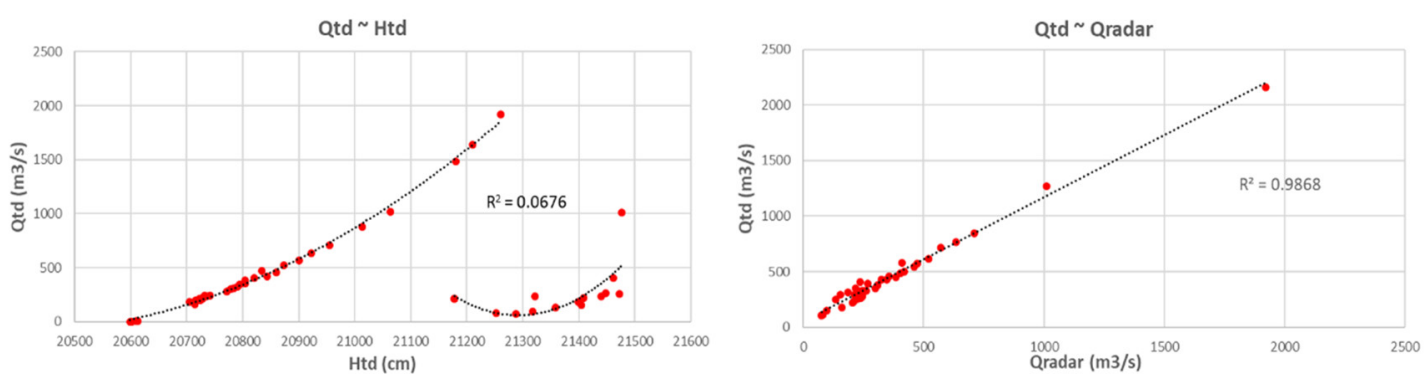

Hình 8. Quan hệ $\mathrm{Q}_{\text {thucdo }} \sim \mathrm{H}_{\text {thucdo }}$ (trái) và quan hệ giữa $\mathrm{Q}_{\text {thucdo }} \sim \mathrm{Q}_{\text {radar }}$ (phải) tại trạm Nậm Giàng. 

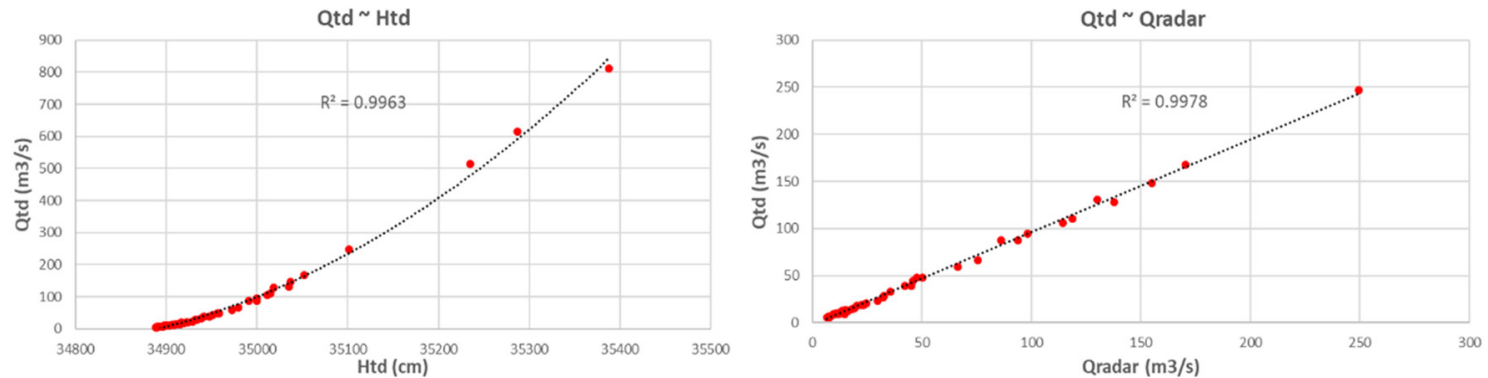

Hình 9. Quan hệ $\mathrm{Q}_{\text {thucdo }} \sim \mathrm{H}_{\text {thucdo }}$ (trái) và quan hệ giữa $\mathrm{Q}_{\text {thucdo }} \sim \mathrm{Q}_{\text {radar }}$ (phải) tại trạm $\mathrm{Na}$ Sang.
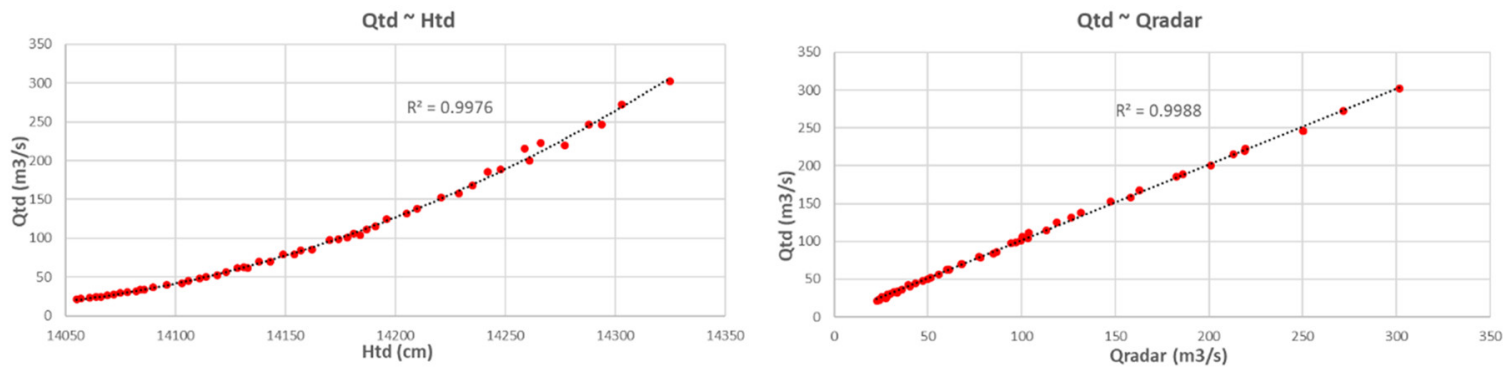

Hình 10. Quan hệ $Q_{\text {thucdo }} \sim H_{\text {thucdo }}$ (trái) và quan hệ giữa $Q_{\text {thucdo }} \sim Q_{\text {radar }}$ (phải) tại trạm Đầu Đẳng.
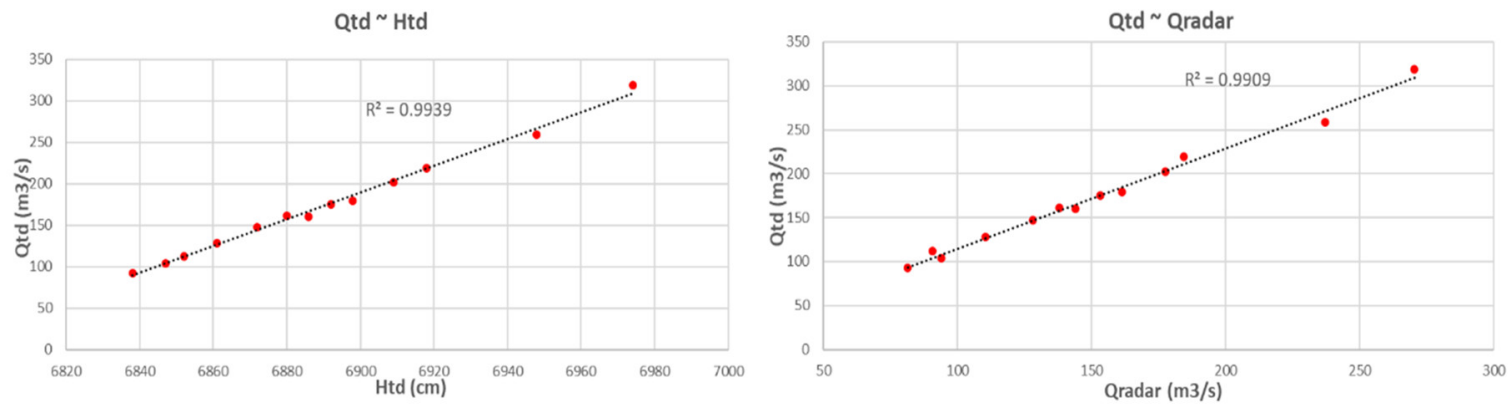

Hình 11. Quan hệ $\mathrm{Q}_{\text {thucdo }} \sim \mathrm{H}_{\text {thucdo }}$ (trái) và quan hệ giữa $\mathrm{Q}_{\text {thucdo }} \sim \mathrm{Q}_{\text {radar }}$ (phải) tại trạm Bảo Yên.
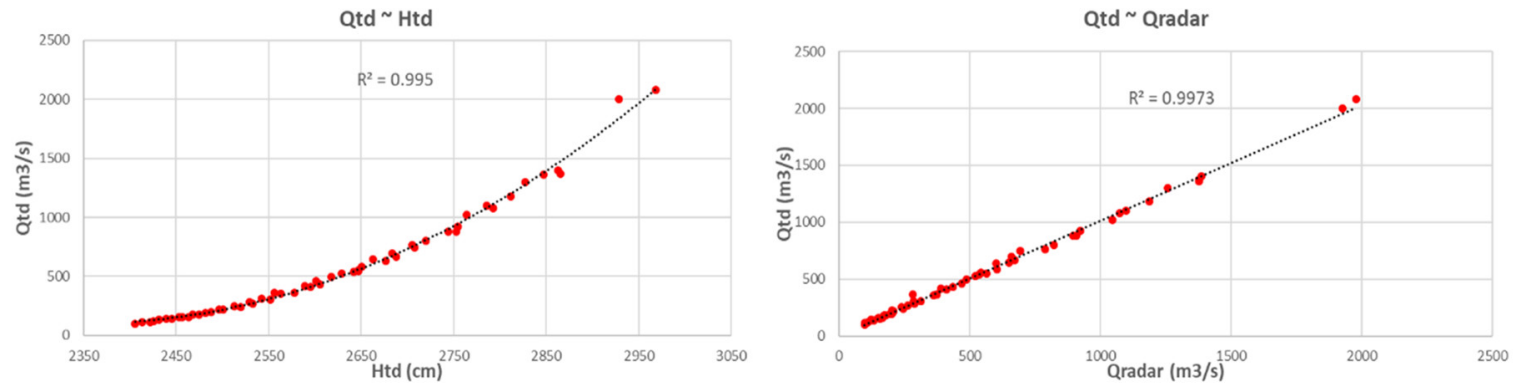

Hình 12. Quan hệ $Q_{\text {thucdo }} \sim H_{\text {thucdo }}$ (trái) và quan hệ giữa $Q_{\text {thucdo }} Q_{\text {radar }}$ (phải) tại trạm Yên Bái.
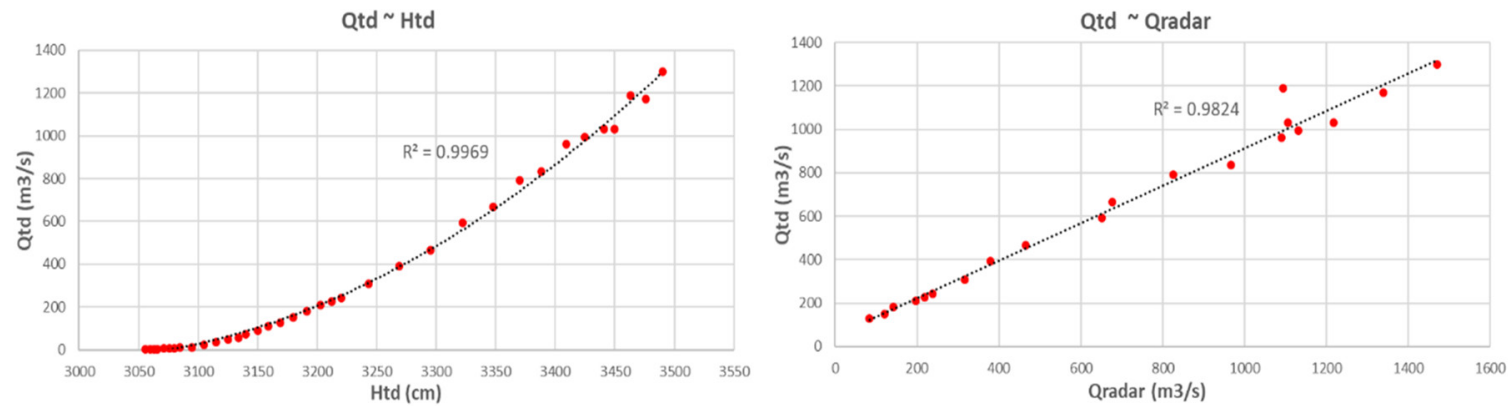

Hình 13. Quan hệ $\mathrm{Q}_{\text {thucdo }} \sim \mathrm{H}_{\text {thucdo }}$ (trái) và quan hệ giữa $\mathrm{Q}_{\text {thucdo }} \sim \mathrm{Q}_{\text {radar }}$ (phải) tại trạm Chiêm Hóa. 

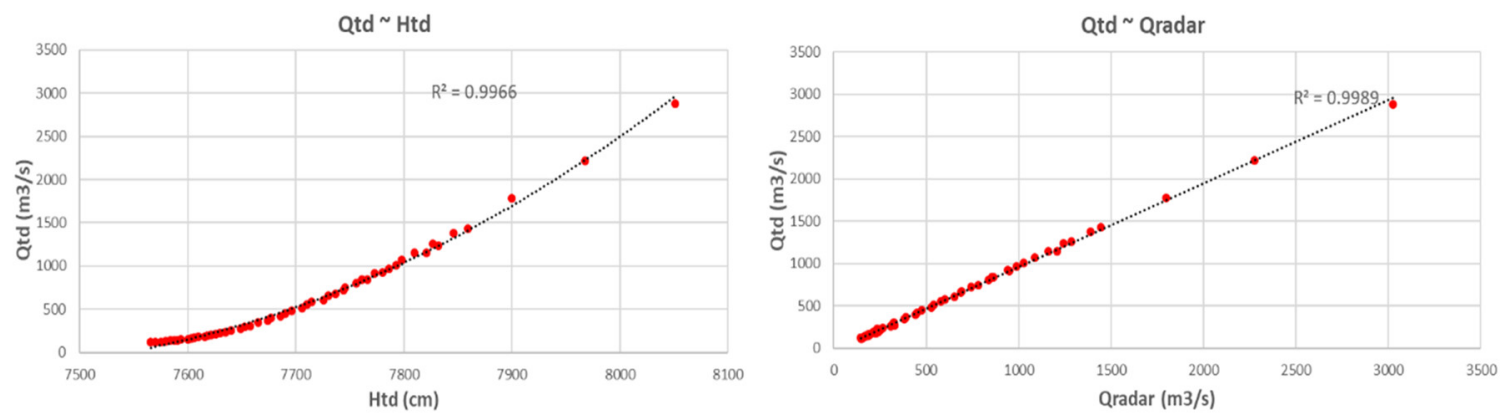

Hình 14. Quan hệ $\mathrm{Q}_{\text {thucdo }} \sim \mathrm{H}_{\text {thucdo }}$ (trái) và quan hệ giữa $\mathrm{Q}_{\text {thucdo }} \sim \mathrm{Q}_{\text {radar }}$ (phải) tại trạm Lào Cai.

Bảng 3. So sánh tương quan của quan hệ $\mathrm{Q}_{\text {thucdo }} \sim \mathrm{H}_{\text {thucdo }}$ và $\mathrm{Q}_{\text {thucdo }} \sim \mathrm{Q}_{\text {radar }}$ tại các trạm.

\begin{tabular}{cccc}
\hline TT & Tên trạm & $\begin{array}{c}\text { Hệ số tương quan } \mathbf{R}^{\mathbf{2}} \\
\left(\mathbf{Q}_{\text {thucdo }} \sim \mathrm{H}_{\text {thucdo }}\right)\end{array}$ & $\begin{array}{c}\text { Hệ số tương quan } \mathbf{R}^{\mathbf{2}} \\
\text { (Q }\end{array}$ \\
\hline 1 & Hòa Bình & 0,9862 & 0,9981 \\
2 & Nậm Giàng & 0,0676 & 0,9868 \\
3 & Na Sang & 0,9963 & 0,9978 \\
4 & Đầu Đẳng & 0,9976 & 0,9988 \\
5 & Bảo Yên & 0,9939 & 0,9909 \\
6 & Yên Bái & 0,995 & 0,9973 \\
7 & Chiêm Hóa & 0,9969 & 0,9824 \\
8 & Lào Cai & 0,9966 & 0,9989 \\
\hline
\end{tabular}

Có thể thấy khá trực quan, nếu sử dụng thêm sensor đo lưu tốc bề mặt tại thủy trực đại biểu về lưu tốc nhằm bổ sung thêm yếu tố trong mối quan hệ lưu lượng-mực nước-lưu tốc bề mặt, kết quả tính toán lưu lượng được cải thiện đáng kể về độ chính xác so với việc sử dụng quan hệ lưu lượng-mực nước truyền thống. Cụ thể, ở một số trạm có mối quan hệ chặt chẽ, tuyến tính giữa lưu lượng và mực nước (như trạm Hòa Bình, $\mathrm{Na}$ Sang, Đầu Đẳng, ...) thể hiện qua hệ số tương quan $\mathrm{R}^{2}>0,9$ thì bổ sung thêm lưu tốc bề mặt vẫn góp phần làm chính xác hơn giá trị lưu lượng với hệ số $\mathrm{R}^{2}$ tăng lên đến 0,99 . Ủu thế về độ chính xác của quan hệ mới này được thể hiện rõ ở một số trạm có dòng chảy phức tạp hơn, khi mối quan hệ Q $\mathrm{H}$ khá phức tạp (như trạm Nậm Giàng có dòng chảy đang chịu ảnh hưởng bởi điều tiết của thủy điện Nậm Na 3 cách trạm khoảng $3 \mathrm{~km}$ ) thì khi có thêm sensor đo lưu tốc, hệ số tương quan đã tăng lên một cách đáng kể đạt $\mathrm{R}^{2} \sim 0,98$.

Tuy nhiên, đối với một số trạm đo có hiện tượng dòng chảy ngược do nước vật hoặc thủy triều, về mặt nguyên lý thì công nghệ đo sẽ không đảm bảo độ chính xác. Nhưng do có hạn chế về số liệu chi tiết thu thập được (tại các trạm đo ADCP chưa trích xuất trực tiếp số liệu quan trắc theo độ sâu trên các thủy trực) nên nghiên cứu này chưa có điều kiện đánh giá.

\section{Kết luận}

Qua các phân tích và đánh giá, có thể nhận thấy ở hầu hết các trạm có số liệu để khảo sát, việc lắp đặt thêm các sensor đo lưu tốc tại thủy trực đại biểu đã lựa chọn, có thể cải thiện được đáng kể chất lượng của giá trị lưu lượng tính toán, đặc biệt tại trạm có chế độ dòng chảy phức tạp như tại trạm Nậm Giàng. U’u thế đối với các trạm đo có đặc tính vòng lũ hay nước vật cũng có thể được làm rõ hơn, tuy nhiên do các trạm lắp đặt $\mathrm{ADCP}$ hiện nay chưa cho phép trích xuất số liệu lưu tốc bề mặt cũng như phương pháp đo giảm điểm trong điều kiện nguy hiểm tại các trạm đã hạn chế cơ hội chứng minh ưu thế này của công nghệ đo Radar.

Tại một số các trạm còn lại như trạm $\mathrm{Na}$ Sang, Đầu Đẳng, ... mặc dầu việc trang bị thêm sensor đo lưu tốc sẽ có cải thiện thêm độ chính xác của lưu lượng tính toán, tuy nhiên do bản thân chế độ dòng chảy tương đối ổn định, lưu lượng tính toán theo quan hệ $\mathrm{Q} \sim \mathrm{H}$ truyền thống đã đảm bảo yêu cầu thì việc bổ sung thêm radar đo lưu tốc sẽ chỉ tăng cường thêm độ chính 
xác (chỉ cần bổ sung sensor đo mực nước liên tục), cần cân nhắc để đảm bảo hiệu quả và tiết kiệm kinh phí đầu tư cũng như duy trì và vận hành.

Mặt khác, nghiên cứu này cũng giới thiệu cách thức để xác định được vị trí lắp đặt các sensor đo lưu tốc (thủy trực "đại biểu”) nhằm đảm bảo độ chính xác của giá trị lưu lượng tính toán. Và đồng thời cũng cho thấy rằng, với bản chất của công nghệ đo, việc xác định các hệ số tương quan là rất cần thiết do đó cần duy trì đủ số lượng quan trắc bằng các phương pháp chi tiết (như sử dụng lưu tốc kế hay $\mathrm{ADCP}$ ) đảm bảo xác định quan hệ ổn định thống kê, đặc biệt khi mặt cắt có sự biến động thì cần tổ chức quan trắc để cập nhật lại hệ số $k$.

Do thời gian và số liệu còn hạn chế, nghiên cứu này chưa đánh giá tính khả thi của công nghệ đo Radar cho các trạm thủy văn có dòng chảy hai chiều và kiến nghị cần có thêm các đánh giá bổ sung chi tiết nhằm làm sáng tỏ hơn các điều kiện áp dụng của công nghệ đo lưu lượng bằng Radar. Kiến nghị Tổng cục Khí tượng Thủy văn yêu cầu quan trắc bổ sung thêm lưu tốc mặt ở các trạm đo ADCP hiện nay, nhằm hỗ trợ các nghiên cứu chi tiết và đầy đủ hơn trong tương lai, hướng đến xây dựng quy trình lắp đặt và quan trắc bằng công nghệ mới nói chung và công nghệ Radar nói riêng tại Việt Nam.

Đóng góp của tác giả: Xây dựng ý tưởng nghiên cứu: T.N.A., L.Đ.D.; Lựa chọn phương pháp nghiên cứu: T.N.A., L.Đ.D., N.P.L.; Thực địa: T.N.A., L.Đ.D., T.V.Q., L.T.M., P.H.D.B., N.V.N.; Xử lý số liệu: L.T.M., T.V.Q., H.T.B., N.V.N., P.D.H.B.; Viết bản thảo bài báo: T.N.A., L.T.M.; Chỉnh sửa bài báo: T.N.A., L.Đ.D., T.V.Q., N.P.L.

Lời cảm ơn: Nghiên cứu này được thực hiện dưới sự tài trợ của đề tài nghiên cứu khoa học cấp Bộ TNMT: "Nghiên cúu, đề xuất đổi mói công nghệ quan trắc, giám sát thủy văn, tài nguyên nước mặt phù hợp với các loại hình sông ở Việt Nam”, mã số TNMT. 2018.02.14, và nhận được sự hỗ trợ nhiệt tình, đầy đủ của các cán bộ thuộc các Đài Khí tượng Thủy văn khu vực Tây Bắc và Việt Bắc, tập thể tác giả xin trân trọng cám ơn.

Lời cam đoan: Tập thể tác giả cam đoan bài báo này là công trình nghiên cứu của tập thể tác giả, chưa được công bố ở đâu, không được sao chép từ những nghiên cứu trước đây; không có sự tranh chấp lợi ích trong nhóm tác giả.

\section{Tài liệu tham khảo}

1. Rantz, S.E. Measurement and computation of streamflow, vol 1., Measurement of stage and discharge. U.S. Geol. Surv. Water Supply Pap. 1982, 2175, pp. 284.

2. Sauer, V.R.; Meyer, R.W. Determination of error in individual discharge measurements. U.S. Geol. Surv. Open File Rep. 1992, 4-6(16), 92-144.

3. Fukami, K.; Yamaguchi, T.; Imamura, H.; Tashiro, Y. Current status of river discharge observation using non-contact current meter for operational use in Japan. World Environmental and Water Resources Congress, Ahupua'a, Hawaii, 2008, pp. $1-10$.

4. Teague, C.C.; Barrick, D.E.; Lilleboe, P.M.; Cheng, R.T. Extended UHF radar observations of river flow velocity and comparisons with in-situ measurements. Proceeding of $9^{\text {th }}$ International Symposium on River Sedimentation, Ministry of Water Resource, Yichang, China, 2004.

5. Plant, W.J.; Keller, W.C.; Hayes, K.; Spicer, K.R. Streamflow properties from time series of surface velocity and stage. J. Hydraul. Eng. 2005, 131(8), 657-664.

6. Costa, J.E.; Spicer, K.R.; Cheng, R.T.; Haeni, F.P.; Melcher, N.B.; Thurman, E.M. Measuring stream discharge by non-contact methods: A proof-of-concept experiment. Geophys. Res. Lett. 2000, 27, 553-556.

7. Costa, J.E.; Cheng, R.T.; Haeni, F.P.; Melcher, N.; Spicer, K.R.; Hayes, E.; Plant, W.; Hayes, K.; Teague, C.; Barrick, D. Use of radars to monitor stream discharge by noncontact methods. Water Resour. Res. 2006, 42, W07422. https://doi.org/10.1029/2005WR004430. 
8. Gupta, R.P.; Bhonde, K.G.; Khandagale, H.R. Testing and Calibration of ContactFree Radar Type Discharge Sensor in Development of Water Resources in India (V. Garg et al. eds.). Water Sci. Technol. Lib. 2017, 75, 407-417.

9. Welber, M.; Le Coz, J.; Laronne, J.B.; Zolezzi, G.; Zamler, D.; Dramais, G.; Hauet, A.; Salvaro, M. Field assessment of noncontact stream gauging using portable surface velocity radars (SVR). Water Resour. Res. 2016, 52, 1-19. https://doi.org/10.1002/2015WR017906.

10. Fulton, J.; Ostrowski, J. Measuring real-time streamflow using emerging technologies: Radar, hydroacoustics, and the probability concept. J. Hydrol. 2008, 357(1), 1-10.

11. Melcher, N. B.; Costa, J.E.; Haeni, F.P.; Cheng, R.T.; Thurman, E.M.; Buursink, M.; Spicer, K.R.; Hayes, E.; Plant, W.J.; Keller, W.C.; Hayes, K. River discharge measurements by using helicopter-mounted radar. Geophys. Res. Lett. 2002, 29(22), 2084. https://doi.org/10.1029/2002GL015525.

12. User Manual of RQ-30, RQ-30a. Discharge Measurement System, Firmware version 1.8x, Sommer Messtechnik, GmbH, A-6842 Koblach, Manual version: V02, 2014.

\title{
Monitoring ability assessment of non-contact Radar technology for stream discharge at hydrological stations in North West - and Central North regions
}

\author{
Tran Ngoc Anh ${ }^{*}$, La Duc Dung², Ly Tuan Minh ${ }^{1}$, Tran Vinh Quang1, Hoang Thai \\ Binh $^{3}$, Pham Duy Huy Binh${ }^{1}$, Nguyen Van Nguyen², Nguyen Phu Luan² \\ ${ }^{1}$ Center for Environmental Fluid Dynamic, VNU University of Science, Vietnam National \\ University, Hanoi (VNU); tranngocanh@hus.edu.vn; lytuanminh122@gmail.com; \\ tranvinhquang@hus.edu.vn; phambinh@hus.edu.vn \\ ${ }^{2}$ Vietnam Meteorological and Hydrological Administration, Ministry of Natural \\ Resources and Environment (MONRE); dunglakttv@gmail.com; \\ nguyentaybac@gmail.com; luansdu@gmail.com \\ ${ }^{3}$ Geology Institute, Vietnam Academy of Science and Technology (VAST); \\ binhht060774@gmail.com
}

\begin{abstract}
Abtract: Modern hydrological monitoring methods toward automated technology like noncontact radar equipment for stream discharge measurement have been considered and implemented in several ODA/ international donor-funded projects since their advantages in extreme conditions having high flow velocity and the presence of debris, drifting logs, and stumps. However, several concerns on the feasibility and accuracy of that equipment that need to be addressed by a detailed assessment and data analysis. Thus, this paper is dedicated to assessing the monitoring abilities of non-contact radar technology for stream discharge monitoring using the observed data at some key hydrological stations in NorthWest, and Central-North regions. The quality of correlation $\mathrm{Q} \sim \mathrm{H}, \mathrm{V}$ surface is assessed versus the conventional $\mathrm{Q} \sim \mathrm{H}$ relation. The results show that beyond the advantages of the automated non-contact equipment, the current Radar technology could provide quite accurate streamflow data at the hydrological stations having stable hydraulic regime, and significantly enhancing the reliability of measurement at other complex hydraulic regime stations although this paper has not yet assessed for the station in the tidal region or having backwater effects.
\end{abstract}

Keywords: Non-contact Radar; stream discharge monitoring; North-West; Central North of Vietnam. 